\title{
GESTÃO FINANCEIRA DAS COOPERATIVAS: APLICAÇÃO DO MODELO DINÂMICO
}

\section{FINANCIAL ADMINISTRATION OF THE COOPERATIVES: APPLICATION OF THE DYNAMIC MODEL}

\author{
António Carlos Vaz Lopes \\ Faculdade Integradas de Naviraí - FINAV-Brasil \\ tonivazlopes@bol.com.br \\ Emilio Araújo Menezes \\ Universidade Federal de Santa Catarina-UFSC- Brasil \\ emilio@eps.ufsc.br
}

\begin{abstract}
Resumo
A gestão do capital de giro é extremamente dinâmica exigindo a atenção diária dos executivos financeiros. Qualquer falha nesta área de atuação poderá comprometer a capacidade de solvência da empresa ou prejudicar a sua rentabilidade. O objetivo desse trabalho é fazer uma análise financeira dinâmica de capital de giro como ferramenta para apoio de tomada de decisões econômica e financeira das empresas. Esse trabalho foi desenvolvido através da análise das demonstrações financeiras dos três últimos periodos de duas empresas agropecuárias. Verificou-se que as duas possuem estruturas de capitais idênticas, apresentando deficiência de tesouraria. A primeira empresa a estrutura vem piorando apontando para o efeito tesoura, já a segunda empresa teve uma melhora substancial na sua estrutura apontando para uma reversão da tesouraria negativa.
\end{abstract}

Palavras-chave: Capital de giro; Estrutura financeira; Estratégias financeiras.

\section{Introdução}

O agronegócio brasileiro vem passando por uma crescente evolução desempenhado um papel importante no desenvolvimento econômico nacional. No ano passado foi responsável por um terço do PIB brasileiro, $42 \%$ das exportações, $37 \%$ dos empregos no país, além de quase um terço das 500 maiores empresas incluídas no ranking da revista exame pertencer.

As cooperativas agropecuárias ocupam um papel de destaque nesse cenário, com número expressivo em relação ao volume de produção, exportação e geração de empregos. O crescimento dessas organizações nos últimos anos pela agregação de valor aos produtos, verticalização das suas operações, trouxe também desafios gerencias para sua permanência no mercado. 
Segundo Gimenes et all (2005) esse novo ambiente de negócios conduz as cooperativas a um momento de reflexão, em que seus dirigentes percebem os novos desafios que deverão enfrentar para sobreviver nesse ambiente de alta turbulência. Por um lado, apresentam-se desafios e oportunidades, mas, por outro, estimulo ' cultura de competição nas sociedades contemporâneas representa uma ameaça ao modelo atual de gestão cooperativista.

Entre os desafios estão aquelas relacionadas a gestão (recursos humanos, processo produtivo entre outros), mas o objetivo desse trabalho é analisar a gestão financeira dessas organizações no que tange a sua estrutura financeira de capital de giro, já que essas decisões afetam a saúde e continuidade das organizações.

A análise das demonstrações financeiras fornece um ponto inicial para se compreender uma empresa, seja ela cooperativa, seja sociedade anônima.

As informações produzidas pela contabilidade através da análise financeira tradicional, têm sido alvo de várias criticas ao longo dos anos quanto ao seu objetivo de geração de informações úteis para tomada de decisões.

Para Hopp e Leite (1989, p.63) A análise financeira tradicional pressupõe a liquidação da empresa no curto prazo, que é primordial que os usuários das demonstrações contábeis estejam cientes da condição estática da informação e que as dúvidas sejam resgatadas pelo fluxo de recursos produzidos pelas operações dos ativos e não pela sua liquidação.

\section{Análise dinâmica}

O modelo de Fleuriet também denominado de análise financeira dinâmica foi desenvolvido na década de 70 pelo Francês Michael Fleuriet juntamente com profissionais brasileiros. O autor sugere uma abordagem diferente para análise financeira tradicional que na opinião de Fleuriet.

De acordo com Brasil e Brasil (1997, p.1) o enfoque tradicional da análise contábil tradicional que está centrada em uma visão estática da empresa, para um enfoque dinâmico.

A análise pelo modelo dinâmico inicia-se com a reclassificação das contas do Balanço em circulante ativo e passivo e permanente.

Para o desenvolvimento do modelo Fleuriet, Kehdy e Blanc (1978) reclassificaram as contas do balanço patrimonial, levando em consideração a velocidade com que as mesmas se movimentam. Segundo os autores existem algumas contas que apresentam uma movimentação tão lenta quando analisadas isoladamente ou em relação ao conjunto de outras contas que, numa análise de curto prazo, porém podem ser consideradas como permanentes ou não cíclicas enquanto outros apresentam um movimento continuo e cíclico, ou mesmo descontinuo ou errático. 
As contas do grupo circulante ativo e passivo são subdivididas conforme sua natureza em operacionais e financeiras, a saber: ativo circulante financeiro (ACF), ativo circulante operacional (ACO), passivo circulante financeiro (PCF) e passivo circulante operacional (PCO).

O ativo circulante operacional (ACO) é composto por contas que giram rapidamente em uma empresa e são necessárias para o ritmo das operações, por isso não podem ser realizadas sob pena de comprometer a continuidade da empresa tais como estoque, duplicatas a receber, despesas pagas antecipadas etc., enquanto o passivo circulante operacional (PCO) é constituído por exigibilidades de curto prazo como duplicatas a pagar, impostos, taxas contas a pagar diversas etc.

$\mathrm{O}$ ativo circulante financeiro (ACF) tem a natureza errática é formado por contas essencialmente financeiras como caixa, bancos, aplicações financeiras de liquidez imediata e aplicações financeiras de curto prazo.

O passivo circulante financeiro (PCO) comporta de natureza errática formada por passivo de curto prazo que provocam despesas financeiras como empréstimos e financiamento com vencimento no curto prazo, duplicatas descontadas.

$\mathrm{Na}$ opinião de Braga (1991) a reclassificação do Balanço Patrimonial deve levar em consideração o fator curto e longo prazo e os níveis de decisão empresarial - estratégico, financeiro e operacional. Portanto dividem-se os itens do ativo e passivo circulante (curto prazo) em operacionais cíclicos e financeiros (erráticos), enquanto as contas de longo prazo serão classificadas como permanente (não cíclico). Nessa classificação as diversas contas estão relacionadas não apenas pela sua relação temporal, mas também pela sua relação no desenvolvimento das atividades operacionais.

Com base no novo balanço patrimonial proposto por Fleuriet pode-se identificar algumas variáveis necessárias para uma análise dinâmica do balanço patrimonial. Essas variáveis são: Necessidade de Capital de Giro (NCG), Capital de Giro (CDG) Saldo de Tesouraria (ST).

\subsection{Necessidade de capital de giro}

A análise do comportamento da NCG é um elemento importante para avaliar a situação financeira das organizações, já que ela evidencia as mudanças ocorridas no negócio.

A necessidade de capital de giro NCG é não só um conceito fundamental para a análise da empresa do ponto de vista financeiro, ou seja, análise de caixa, mas também de estratégias de financiamento, crescimento e lucratividade. Matarazzo (2003: p.337).

Ela pode ser mensurada em termos de dias ou em termos monetários através da diferença entre o ativo circulante operacional e passivo circulante operacional

$$
\mathrm{NCG}=\mathrm{ACO}-\mathrm{PCO}
$$


O conceito de Necessidade de Capital de Giro segundo Fleuriet Kedy e Blanc (1978) decorrem da necessidade de caixa, no momento em que, no ciclo financeiro, as saídas de ocorrem antes das entradas.

Se o saldo for positivo significa que a empresa precisa de capital de giro para a qual deve encontrar fontes adequadas de financiamento, já quando o saldo for negativo ela possui recursos excedentes, que podem ser utilizados para aplicação no mercado financeiro ou para expansão da planta fixa.

Como as contas que fazem parte do circulante cíclico estão vinculadas ao ciclo operacional da empresa toda as alterações ocorridas tanto em tempo de volume quanto em tempos de prazos afetam diretamente o montante dos ativos e passivos cíclicos.

\subsection{Capital de giro}

Uma outra variável importante utilizado pelo Modelo de Fleuriet é o do Capital de Giro (CDG) obtido através da diferença entre passivo não circulante e ativo não circulante ao contrário da visão tradicional denominada de capital circulante liquido CCL definido pela diferença entre ativo e passivo circulante.

$$
\mathrm{CDG}=\mathrm{PCN}-\mathrm{ANC}
$$

Quando o CDG for negativo significa que há recursos de curto prazo financiando ativos não circulantes, quando o CDG for positivo mostra que os recursos de longo prazo além de financiar ativo não circulante financiam também ativo circulante.

\subsection{Tesouraria}

O Saldo de Tesouraria (ST) é obtido através da diferença entre ativo circulante financeiro e passivo circulante financeiro ou, pela diferença entre o CDG e NCG e revela (evidencia) a margem de segurança financeira.

$$
\mathrm{ST}=\mathrm{ACF}-\mathrm{PCF}
$$

$$
\mathrm{ST}=\mathrm{CDG}-\mathrm{NCG}
$$

ou 
Segundo Santi Filho e Olinquevitch (1995, p.25) A variável Tesouraria, é sem duvida, aquela que melhor expressa a situação financeira de curto prazo das empresas. O seu saldo positivo, indica uma situação financeira folgada; se o saldo for negativo, indica a utilização de recursos de terceiros para financiar as atividades operacionais da empresa.

Ciclo Financeiro (CF) o ciclo financeiro é o período compreendido entre o pagamento de fornecedores e o recebimento de clientes incluindo no intervalo vários desembolsos referentes a salários, impostos encargos etc.

O ciclo operacional financeiro possui todos os componentes da necessidade de capital de giro como duplicatas a receber, estoques, fornecedores impostos etc. É obtido a partir da seguinte formula.

\subsection{Termômetro da Situação Financeira TSF}

$$
\mathrm{N}=\frac{\mathrm{NCG}}{\text { Vendas }} \times 100
$$

A relação T- Tesouraria dividida pela NCG Necessidade de capital de giro é o verdadeiro termômetro da situação de liquidez da empresa. Santi Filho e Olinquevitch (1995, p.42)

\subsection{Efeito Tesoura}

A empresa convive, com efeito, Tesoura quando ela apresenta por vários exercícios seguidos a Necessidade de Capital de giro superior ao capital de Giro liquido.

$\mathrm{O}$ efeito tesoura demonstra que a empresa é incapaz de financiar adequadamente as suas dividas

Tabela 1 - Posicionamento financeiro da empresa com base nas variáveis - NCG: CDG e ST.

\begin{tabular}{|c|c|c|c|c|}
\hline Tipo/Item & CDG & NCG & ST & Situação \\
\hline I & + & - & + & Excelente \\
\hline II & + & + & + & Sólida \\
\hline III & + & + & - & Insatisfatória \\
\hline IV & - & - & + & Alto risco \\
\hline V & - & - & - & Muito ruim \\
\hline VI & - & + & - & Péssima \\
\hline
\end{tabular}

Fonte: Marques e Braga (1995). 


\section{Metodologia}

A realização desse trabalho foi desenvolvida através do estudo de caso duas cooperativas agropecuárias de Mato Grosso do Sul. Os dados analisados referem às demonstrações contábeis publicadas nos últimos três exercícios 2002, 2003 e 2004. A análise foi desenvolvida perseguindose as seguintes etapas:
a) Padronização
b) Cálculo dos índices
c) Ponderação das informações extraídas dos índices
d) Diagnóstico
e) Considerações.

\section{Análise dos Resultados}

Com a reclassificação do balanço patrimonial conforme o modelo dinâmico de análise da situação financeira foi possível determinar as seguintes variáveis que compõem a estrutura de capitais da empresa resumida no quadro abaixo:

Tabela 2 - Estrutura de capitais da empresa A

\begin{tabular}{lccc}
\hline VARIÁVEIS & $\mathbf{2 0 0 2}$ & $\mathbf{2 0 0 3}$ & $\mathbf{2 0 0 4}$ \\
\hline Vendas Médias & 97.467 .621 & 117.720 .727 & 119.305 .858 \\
Capital de Giro & 15.850 .559 & 17.390 .239 & 18.101 .148 \\
Nec. De Capital de Giro & 17.538 .804 & 24.859 .419 & 38.851 .032 \\
Longo Prazo & 15.850 .559 & 17.390 .238 & 18.101 .148 \\
Saldo de Tesouraria & -1.688 .225 & -7.469 .180 & -20.749 .883 \\
Ciclo Financeiro & 65 & 76 & 117 \\
Termom da Sit. Financeira & $-0,10$ & $-0,30$ & $-0,53$ \\
\hline
\end{tabular}

Fonte: dados da pesquisa

As vendas da empresa A cresceram 20,77\% no ano de 2003 atingindo um valor de 117.720 mil, crescimento satisfatório quando comparada com empresas de outros setores. Em 2004 o faturamento cresceu apenas 1,35\% valor muito aquém da sua média histórica e do setor, provocada situação conjuntural (queda na produtividade provocada pela estiagem) e na cotação dos produtos agrícolas. Nota-se que apesar de não ser uma grande cooperativa o seu faturamento é superior a maioria das empresas brasileiras.

A estrutura financeira de capital de giro da empresa em 2002 revela que a empresa possui recursos próprios para imobilização (capital de giro positivo) no valor de 15.850 mil, porém insuficiente para cobertura das necessidades de capital de giro que é de 17.538 mil resultando no 
saldo de tesouraria negativo de $1.688 \mathrm{mil}$, com isso a empresa necessita captar recursos de curto prazo de terceiros instituições financeiras ou fornecedores para cobrir o déficit, sujeito ao pagamento de juros.

O capital de giro da empresa manteve positivo nos anos seguintes, mas a diferença entre a NCG e CDG continuou crescendo conseqüentemente ampliando o saldo negativo de tesouraria. Em 2003 a deficiência de tesouraria aumentou expressivamente $342 \%$ em relação ao ano anterior, atingindo R\$7.469 mil. No exercício seguinte a estrutura financeira piorou e a deficiência de tesouraria atingiu 20.750, mil, dobro do valor de suas vendas mensais. Esta situação é decorrente de uma estratégia financeira que levou a empresa a aumentar seu capital de giro em apenas $4 \%$, valor muito aquém do aumento da NCG que teve um aumento considerável de 56\% isso fez agravar demasiadamente o saldo negativo de tesouraria levando a empresa a tornar mais dependente de recursos de curto prazo para financiar suas atividades, tornando-se mais vulnerável.

Apesar desse déficit não depender apenas de decisões dos seus gestores, não poderia deixar de frisar que a estratégia financeira adotada contribuiu para essa situação talvez até inconscientemente, mas considerando que o país é dono das maiores taxas de juros do mundo esses valores afetam a rentabilidade da empresa.

Quando uma empresa apresenta por vários exercícios seguidos um crescimento do NCG superior ao do CDG, diz-se que ela convive com o denominado efeito tesoura. Pela análise dos três períodos podemos afirmar que esse fenômeno está bastante representativo na empresa A.

Uma das razões a qual pode-se indicar como provável causa para este efeito tesoura é o aumento progressivo do seu ciclo financeiro em 2002 era de 65 dias muito além do normal 30 dias, chegando a 117 dias em 2004, fenômeno que provoca o aumento das necessidades de capital de giro da empresa Essa situação revela que a empresa vem aumentando a utilização de recursos de terceiros de curto prazo (financiamento) para cobrir.

Finalmente procurou-se analisar a estrutura de risco da empresa com base na classificação proposta por Braga. Dado que CDG $>0$ e NCG $>0$, sendo $\mathrm{CDG}<\mathrm{NCG} \operatorname{logo} \mathrm{T}<0$ e $\mathrm{T}<\mathrm{CDG}<$ NCG, classifica-se a empresa como situação financeira insatisfatória, uma vez que o capital de giro é insuficiente para atender todas as necessidades de capital de giro. Segundo Braga (1991) Empresas com este tipo de estrutura patrimonial são bastante dependentes de empréstimos de curto prazo para financiar suas operações. Persistindo essa situação pode culminar com a falência.

A tesouraria negativa passou de $10 \%$ para $53 \%$ do valor da $\mathrm{NCG}$, representando $17 \%$ das vendas do ano de 2004 revela uma incômoda e preocupante tendência das variáveis empresariais. 
Tabela 3 - Estrutura de Capitais da empresa B

\begin{tabular}{lccc}
\hline \multicolumn{1}{c}{ ITENS } & $\mathbf{2 0 0 2}$ & $\mathbf{2 0 0 3}$ & $\mathbf{2 0 0 4}$ \\
\hline Vendas Médias & 61.237 .706 & 129.873 .538 & 157.804 .330 \\
Capital de Giro & 9.064 .475 & 11.611 .927 & 20.311 .461 \\
Nec. De Capital de Giro & 9.917 .455 & 17.946 .209 & 21.566 .180 \\
Longo Prazo & 9.064 .475 & 11.611 .927 & 20.311 .460 \\
Saldo de Tesouraria & -852.980 & -6.334 .282 & -1.254 .720 \\
Ciclo Financeiro & 58 & 50 & 49 \\
Termom. da Sit. Fiananc & $-0,09$ & $-0,35$ & $-0,06$ \\
\hline
\end{tabular}

Fonte: dados da pesquisa

A empresa $\mathbf{B}$ também pode ser considerada de grande porte com faturamento na ordem de 61.237 mil no ano de 2002. A semelhança da outra empresa analisada em 2002 apresentou o saldo de tesouraria negativa, porém um valor bem menor de R \$ 853 mil. As vendas em 2003 tiveram uma forte expansão aumentando $121 \%$, em relação ao ano anterior, motivada pelo aumento dos preços no mercado internacional.

Essa expansão fez aumentar as necessidades de capital de giro em $81 \%$ no ano de 2003 em relação a 2002 que passou de $\mathrm{R} \$ 9.917$ mil para $\mathrm{R} \$ 17.946$ mil, enquanto o capital de giro da empresa cresceu apenas 28\%. Esse crescimento desproporcional entre CDG e NCG fez agravar a situação da tesouraria negativa que passou de $9 \%$ para $35 \%$ do valor da NCG, indicando que a empresa precisa recorrer a capital de terceiros de curto prazo para financiar seu giro de caixa. O elevado crescimento nas vendas foi responsável pela tesouraria já que o ciclo financeiro da empresa caiu de 58 para 50dias.

No ano de 2004 o faturamento cresceu $21 \%$ valor bem abaixo do ano anterior, mas valor expressivo comparando com a média das empresas nacionais. A empresa B conseguiu reverter a situação financeira no tocante a tesouraria já que o aumento dos recursos do capital de giro foi maior do que as suas necessidades enquanto o CDG subiu $74,91 \%$ a NCG apenas $20,17 \%$ isso fez o saldo de tesouraria cair aproximadamente $80 \%$ atingindo um patamar de 1.255 mil negativos,com a melhora de captação de recursos de longo prazo com isso a empresa passou a buscar menos recursos de curto prazo de terceiros.

Analisando a estrutura de risco da empresa verificou-se que ela apresenta a mesma estrutura da outra analisada, ou seja, $\mathrm{CDG}>0$ e $\mathrm{NCG}>0$, sendo $\mathrm{CDG}<\mathrm{NCG} \log$ o $\mathrm{T}<0$ e $\mathrm{T}<\mathrm{CDG}<$ NCG, classifica-se a empresa como situação financeira insatisfatória, porém deve-se ressaltar que a tesouraria negativa da empresa é bem menor quando comparada com a empresa $\mathrm{A}$ tornando menos dependente de recursos de terceiros de curto prazo já que ela aumentou a captação de recursos de longo prazo. Isso mostra que a estratégia financeira de substituição na captação de 
recursos de curto para longo prazo aliado a redução do ciclo financeiro da empresa provoca efeitos satisfatórios para a instituição principalmente na redução do pagamento de juros.

\title{
5. Considerações Finais
}

Através da análise dinâmica das demonstrações contábeis verificou-se que as duas cooperativas apresentaram uma estrutura de risco idêntico apresentado por Braga (1991) situação

financeira insatisfatória com saldo de tesouraria negativo nos três períodos analisados, isso pode levar a pensar que é uma característica do setor utilizam recursos financeiros de curto prazo para financiar suas necessidades liquidas de capital de giro, já que pesquisas realizadas com outras cooperativas e em outros estados mostraram essa mesma tendência.

Pelas informações extraídas dos índices financeiros verifica-se que a cooperativa B conseguiu melhorar a sua estrutura financeira no último exercício reduzindo a participação de capitais de terceiros de curto prazo no financiamento das suas necessidades liquidas, diminuindo ainda o ciclo financeiro, eliminando parcialmente o efeito tesoura. A estrutura financeira da cooperativa A piorou sensivelmente nos três períodos analisados devido ao elevadíssimo grau de desequilíbrio entre as fontes e aplicações de recursos principalmente pela diferença entre a variável NCG e CDG gerando um buraco financeiro de 38.851 mil (20.750 mil + 15850 mil), levando a empresa a utilizar recursos de curto prazo e um crescimento de Tesouraria negativa estaria caminhando a empresa ao Efeito Tesoura, provocado principalmente pelo elevado ciclo financeiro da empresa que passou de 65 dias para 117 dias.

\begin{abstract}
The administration of the working capital is extremely dynamic demanding the financial executives' daily attention. Any flaw in this area of performance can commit the capacity of solvency of the company or to harm its profitability. The objective of this work is to make one analysis financial working capital dynamics as tool for support of economic and financial taking of decisions of the companies. That work was developed through the analysis of the financial demonstrations of the last three periods of two agricultural companies. It was verified that the two possess structures of identical capitals, presenting treasury deficiency. The first company the structure comes worsening pointing for the effect scissors, the second company already had a substantial improvement in its structure pointing for a reversion of the negative treasury.
\end{abstract}

Keywords: Working Capital, Structures Financial; Financial Strategies,

\section{Referências}

ASSAF NETO, Alexandre. Estrutura e Análise de Balanços: um enfoque econômico-financeiro. 7. ed. São Paulo: Atlas, 2002.

BRAGA, R. Análise avançada de capital de giro. Cadernos de Estudo, São Paulo: FIPECAFI. n. 3. p. 14 -34, 1999. 
BRASIL, H.V.; BRASIL.H.G. Gestão financeira das empresas: um modelo dinâmico. Rio de janeiro: Qualitimark, 1999.

GIMENES,R.T. Fontes de Financiamento das necessidades de capital de giro em cooperativas agropecuárias: aplicações do modelo dinâmico de análise financeira. RBC, n. 153, 2005.

HOOP, J.L.; LEITE, H.P. O mito de liquidez. Revista de Administração de Empresas. São Paulo, v. 29 n. 4, p. 63-69, 1989.

MATARAZZO, D.C Análise Financeira de balanços: abordagem básica e gerencial 6.ed. São Paulo: Atlas. 2003.

\section{Dados completos do primeiro autor:}

Nome completo: António Carlos Vaz Lopes

Filiação institucional: Faculdades Integradas de Naviraí, Coordenador do curso de Ciências Contábeis.

Endereço para correspondência

Rua Francisco Umburanas 428, Jd. Progresso Naviraí-MS. Cep 79950-000

Telefones para contato (67) 34612380

e-mail: antoniovazlopes@hotmail.com

Recebido para publicação em: 14/10/2005

Aceito para publicação em: 16/02/2006 